\title{
The protective effects of liguzinediol on congestive heart failure induced by myocardial infarction and its relative mechanism
}

Qi Chen ${ }^{1 \dagger}$, Dini Zhang ${ }^{4 \dagger}$, Yunhui Bi ${ }^{1}$, Weiwei Zhang ${ }^{1}$, Yuhan Zhang ${ }^{1}$, Qinghai Meng ${ }^{1}$, Yu Li $^{2^{*}}$ and Huimin Bian ${ }^{1,3^{*}}$

\begin{abstract}
Background: Heart failure (HF) is one of the most common causes of cardiovascular diseases in the world. Currently, the drugs used to treat HF in the clinic may cause serious side effects. Liguzinediol, 2, 5-dimethyl-3, 6-dimethylpyrazine, is a compound synthesized after the structural modification of ligustrazine (one active ingredient of Szechwan Lovage Rhizome). We aimed to observe the effects of liguzinediol on preventing HF and explore the related mechanisms.
\end{abstract}

Methods: The ligation of left anterior descending coronary artery was operated to established the myocardial infarction (MI) model in Sprague-Dawley rats. Cardiac functions were recorded by echocardiography and hemodynamics. The changes in the Renin-Angiotensin-Aldosterone System (RAAS), inflammation, and oxidative stress were detected by radioimmunoassay and Elisa kits. Western blot and real-time PCR were applied to determine the expressions of the TGF- $\beta 1 /$ Smads pathway.

Results: Firstly, liguzinediol enhanced the systolic and diastolic functions of the heart in MI rats. Liguzinediol improved ventricular remodeling by reducing myocardial cell necrosis, as well as reducing collagen deposition and myocardial fibrosis. Then, liguzinediol suppressed the activation of RAAS, inhibited the synthesis of pro-inflammation factors, and reduced oxidative stress. In the end, liguzinediol also down-regulated the expressions of the TGF- $\beta 1 / S$ mads pathway.

Conclusions: Liguzinediol could alleviate HF caused by Ml in rats, and the protective effect was associated with the regulation of the TGF- $\beta 1 /$ Smads pathway.

Keywords: Liguzinediol, Heart failure, Myocardial infraction, TGF- $\beta 1 /$ Smads

\section{Background}

Heart failure (HF) is one of the most common causes of cardiovascular diseases with high morbidity and mortality [1]. As the average age of the population increases

\footnotetext{
*Correspondence: liyu@njucm.edu.cn; hmbian@sina.com

${ }^{\dagger} \mathrm{Qi}$ Chen and Dini Zhang contributed equally to this manuscript

1 School of Pharmacy, Nanjing University of Chinese Medicine, Xianlin Avenue, Qixia District, Nanjing 210023, Jiangsu, China

2 School of Medicine and Life Sciences, Nanjing University of Chinese Medicine, Xianlin Avenue, Qixia District, Nanjing 210023, Jiangsu, China

Full list of author information is available at the end of the article
}

[2], the epidemic trend of HF also rises rapidly. Most patients with HF have a history of myocardial infarction and left ventricular remodeling [3]. The symptoms are characterized by thinning of the myocardium at the site of injury, compensatory hypertrophy of the myocardium, and enlargement of the ventricular cavity. HF has gradually become a major public health problem in China [4]. At present, clinically used anti-HF drugs are diuretics, angiotensin-converting enzyme inhibitors (ACEI), and cardiac glycosides [5]. However, these

c) The Author(s) 2020. This article is licensed under a Creative Commons Attribution 4.0 International License, which permits use, sharing, adaptation, distribution and reproduction in any medium or format, as long as you give appropriate credit to the original author(s) and the source, provide a link to the Creative Commons licence, and indicate if changes were made. The images or other third party material in this article are included in the article's Creative Commons licence, unless indicated otherwise in a credit line to the material. If material is not included in the article's Creative Commons licence and your intended use is not permitted by statutory regulation or exceeds the permitted use, you will need to obtain permission directly from the copyright holder. To view a copy of this licence, visit http://creativecommons.org/licenses/by/4.0/. The Creative Commons Public Domain Dedication waiver (http://creativecommons.org/publicdomain/zero/1.0/) applies to the data made available in this article, unless otherwise stated in a credit line to the data. 
drugs can also cause serious side effects when improving the functions of the heart. For example, the safety window of cardiac glycosides is very narrow, and the dose of mild poisoning is about twice the effective therapeutic dose. In the case of myocardial ischemia and hypoxia, the poisoning dose is lower [6]. ACEI can cause transient deterioration of renal function [7], and long-term use of diuretics is prone to electrolyte disorders. Therefore, researchers have never stopped the development of new anti-HF drugs in order to improve the prognosis of HF patients while reducing toxic side effects.

Liguzinediol, 2, 5-dimethyl-3, 6-dimethyl-pyrazine, is a derivative that takes ligustrazine as the lead compound for structural modification [8, 9] (Fig. 1). Liguzinediol could significantly enhance left ventricular contractility and improve the diastolic function of rat heart without arrhythmia and other adverse effects [10, 11]. Liguzinediol has the advantages of low toxicity and good water solubility, which has laid a good foundation for the research and development of non-digitalis positive inotropic drugs [12]. Our previous study revealed that liguzinediol could improve myocardial cell apoptosis in stress-induced HF [13]. But it is still unknown whether liguzinediol can improve HF caused by primary myocardial damage. In this study, we aimed to establish a model of HF caused by myocardial infarction in rats and to investigate the protective effect of liguzinediol on HF caused by myocardial infarction. As transforming growth factor- $\beta 1$ (TGF- $\beta 1$ )/Smads pathway plays an essential role in the pathogenesis of HF, we also designed to detect the effects of liguzinediol on TGF- $\beta 1 /$ Smads pathway.

\section{Materials and methods Reagents}

Liguzinediol (purity $>98 \%$ ) was provided and synthesized by Professor Wei Li from Nanjing University of Chinese Medicine. The structure was elucidated and confirmed in the previous study [8]. The international patent protection of liguzinediol has been applied (No. PCT/ CN2009/075100). Captopril and Digoxin were purchased from Shanghai Sine Pharmaceutical Co., Ltd (Shanghai, China). Sodium chloride, heparin, chloral hydrate, and penicillin sodium were obtained from Sigma-Aldrich (St. Louis, USA). All Elisa kits were purchased from MultiSciences (Lianke) Biotech Co., Ltd. (Hangzhou, China), and all antibodies were obtained from Abcam (Cambridge, UK).

\section{Myocardial infarction model and drug administration}

A total of eighty male Sprague-Dawley rats (weighting 250-300 g) were obtained from Nanjing Biomedical Research Institute of Nanjing University. All rats were housed in a stable environment at a temperature of $23 \pm 1{ }^{\circ} \mathrm{C}$, the humidity of $40 \pm 5 \%$, and on a $12 \mathrm{~h}$ lightdark cycle. The standard diet and drinking water were supplied for rats with free access. The animal experiments were performed by the Guidelines and Policies for Animal Surgery provided by Nanjing University of Chinese Medicine, and the study was approved by the Institutional Ethics Committee of Animal Care (A171002).

Rats were intraperitoneally anesthetized with $10 \%$ chloral hydrate $(300 \mathrm{mg} / \mathrm{kg})$, and then intubated and ventilated with an automatic breathing apparatus (tidal volume: $10-12 \mathrm{ml}$; respiratory rate: 90 cycles $/ \mathrm{min}$; respiration ratio: 1:2). According to the previous study [14, 15], the myocardial infarction model was established by permanent left anterior descending coronary artery ligation. Briefly, the left anterior descending coronary artery was ligated at approximately $2-3 \mathrm{~mm}$ distal from its origin with the use of a 6-0 silk suture. Then the chest was closed immediately. A similar surgical procedure was performed in the sham group of rats without coronary artery ligation. Two weeks after surgery, ejection fraction (EF) was measured by echocardiography. Rats with $\mathrm{EF}<55 \%$ were randomly divided into seven groups, including sham group, MI group, Captopril group (10 mg/kg), Digoxin group $(0.032 \mathrm{mg} / \mathrm{kg})$, low-liguzinediol group $(5 \mathrm{mg} / \mathrm{kg})$, medium-liguzinediol group $(10 \mathrm{mg} / \mathrm{kg})$, high-liguzinediol group $(20 \mathrm{mg} / \mathrm{kg})$. There were ten rats in each experiment group, and they were orally administrated by drugs or vehicle for 8 weeks.

\section{Echocardiography and hemodynamic measurements}

After the anesthetic, rats underwent 2D echocardiography using an echocardiographic machine (VisualSonics Vevo2100, Canada). Echocardiographic parameters were recorded as described previously [16], including ejection fraction (EF), left ventricular fractional shortening (LVFS), LV end-systolic dimension (LVEDs) and LV end-diastolic dimension (LVEDd). Stroke volume (SV) was calculated as SV $=$ LVEDd - LVEDs, and cardiac output $(\mathrm{CO})$ was calculated as $\mathrm{CO}=\mathrm{SV} \times \mathrm{HR}$ (heart rate). In addition, the hemodynamic parameters were detected by RM6240 multi-channel physiological signal acquisition and processing system (Chengdu instrument factory, China), including heart rate (HR), LV systolic pressure (LVSP), LV end-diastolic pressure (LVEDP), maximal rate of the increase of $L V$ pressure $\left(+d p / \mathrm{dt}_{\max }\right)$ and maximal rate of the decrease of $L V$ pressure $\left(-\mathrm{dp} / \mathrm{dt}_{\text {max }}\right)$, systolic blood pressure (SBP), diastolic blood pressure (DBP) and mean artery pressure (MAP).

\section{Biochemical assays}

Blood was collected and placed at room temperature for $2 \mathrm{~h}$. Serum was obtained by centrifugation at $3000 \mathrm{rpm}$ 


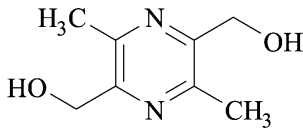

Fig. 1 The chemical structure of liguzinediol

for $10 \mathrm{~min}$ and stored at $-80{ }^{\circ} \mathrm{C}$. Serum inflammatory cytokines tumor necrosis factor $\alpha$ (TNF- $\alpha$ ), interleukin 6 (IL-6) and interleukin $1 \beta$ (IL-1 $\beta$ ) were detected by Elisa kits. The concentrations of angiotensinII (AngII), aldosterone (ALD), and plasma renin activity (PRA) were quantified by radioimmunoassay according to the manufacturer's protocols. The levels of superoxide dismutase (SOD) and malondialdehyde (MDA) were assayed by chemichromatometry according to the directions of kits (Jiancheng Bioengineering Institute, Nanjing, China).

\section{Histological examination}

After weighting, the hearts were fixed in $10 \%$ buffered formalin. Paraffin was used to embedded 2-mm-thick slices of the ventricle and then cut into $4 \mu \mathrm{m}$ sections. The sections were stained by hematoxylin and eosin (H\&E), and five fields were randomly selected on each section to observe [17].

\section{Measurement of myocardial HYP}

According to the instructions of the hydroxyproline assay kit (Nanjing Jiancheng Bioengineering Institute, Nanjing, China), the content of myocardial HYP was detected by alkaline hydrolysis. Briefly, the $\mathrm{pH}$ of the hydrolyzed homogenate was adjusted to 6.0-6.8. Then a blank tube (containing sterile distilled water) and a standard tube (containing $5 \mathrm{mg} / \mathrm{ml}$ standard application solution) were prepared. The absorbance of each sample was analyzed at $550 \mathrm{~nm}$. The content of myocardial HYP was calculated using the following formula:

$$
\begin{aligned}
\operatorname{HYP} & (\mu \mathrm{g} / \mathrm{mg}) \\
= & (\text { absorbance of test tube }- \text { absorbance of blank tube }) \\
& /(\text { absorbance of standard tube }- \text { absorbance of blank tube }) \\
& \times \text { content of standard tube }(5 \mu \mathrm{g} / \mathrm{ml}) \\
& \times \text { volume of hydrolysate }(10 \mathrm{ml}) / \text { wet weight of tissue }(\mathrm{mg}) .
\end{aligned}
$$

\section{Evaluation of collagen deposition}

As mentioned before, the sections of paraffin-embedded hearts were hydrated and stained with Masson Trichrome stain (Sigma, St. Louis, MO, USA). Interstitial collagen was indicated as the percentage of blue staining. Three non-consecutive serial sections were taken from each heart, and five fields were randomly selected on each section. Also, the levels of collagen I and collagen III in serum were detected by Elisa kits.

\section{Ultrastructural observation}

The heart tissues, about $1.0 \mathrm{~mm} \times 1.0 \mathrm{~mm} \times 1.0 \mathrm{~mm}$ in each group, were fixed with $2.5 \%$ glutaraldehyde overnight and washed three times with $0.1 \mathrm{~mol} / \mathrm{l}(\mathrm{pH} 7.2)$ phosphate buffer, then fixed with $1 \%$ osmium tetraoxide at $4{ }^{\circ} \mathrm{C}$, washed with $0.1 \mathrm{~mol} / \mathrm{l}$ phosphate buffer again, and dehydrated by ethanol at different concentrations. Epon812 resin/acetone (1:1) was applied to immerse samples for $1.5 \mathrm{~h}$. Then, samples were soaked in fresh Epon 812 resin for $30 \mathrm{~min}$, and embedded for convergence overnight at $70{ }^{\circ} \mathrm{C}$ [18]. The tissue was cut into 60-80 nm thick slices. The ultrastructure of cardiac muscle cells was observed on transmission electron microscopy (JEM-1010, Hitachi, Tokyo, Japan).

\section{Western Blot analysis}

The expressions of proteins involved in the TGF- $\beta 1$ / Smads pathway were detected. According to the instruction, the concentration of protein was identified by the BCA assay kit (Beyotime). Then $30 \mu \mathrm{g}$ proteins were separated by $10 \%$ SDS-PAGE and were transferred to PVDF membranes. After blocking, the primary antibodies were incubated with membranes at $4{ }^{\circ} \mathrm{C}$ overnight. Then the secondary antibody was used to incubate membranes for $90 \mathrm{~min}$. In the end, the target proteins were determined with an ECL system (Millipore) and visualized by a ChemiDoc XRS system (Bio-Rad).

\section{Real-time polymerase chain reaction (PCR)}

The mRNA levels of genes involved in the TGF- $\beta 1 /$ Smads pathway were detected by the quantitative RTPCR. TRIzol reagent (Invitrogen, Carlsbad) was used to isolate total RNA of J774A-1 cells. RNA was reversely transcribed into cDNA by the First Strand cDNA Synthesis kit (Thermo Fisher Scientific). The primer sequences were presented in Table 1 . The Real-time PCR reaction was amplified by using ABI QuantStudio6 Q6 with AceQ qPCR SYBR ${ }^{\circledR}$ Green Master Mix (Vazyme).

\section{Statistical analysis}

The data were statistically analyzed by one-way ANOVA followed by Tukey's multiple comparison tests employing Prism (Version 6.0; GraphPad Software Inc.). Data are expressed as mean \pm SD. Statistical significance was accepted at the $P$ value of $<0.05$. 


\section{Results}

Effects of liguzinediol on echocardiographic parameters in $\mathrm{MI}$ rats

As shown in Table 2, before administration, the data showed that EF, LVFS, SV, and CO significantly decreased. In addition, LVEDs and LVEDd dramatically increased in MI rats. There were significant differences when compared to the sham group, which indicates that the heart failure rat model was successfully established.

At the end of administration for 8 weeks, EF and LVFS in MI rats continued to decline, LVEDs and LVEDd increased as well. Although SV and CO also increased, the difference was still significant compared with the sham group. The results implied that the heart failure of rats was not significantly improved. CO increased significantly in all administration groups. EF and LVFS were up-regulated in Captopril (10 mg/kg) and three liguzinediol $(5,10,20 \mathrm{mg} / \mathrm{kg})$ groups. SV improved in Digoxin $(0.032 \mathrm{mg} / \mathrm{kg})$ and two liguzinediol (10, $20 \mathrm{mg} / \mathrm{kg})$ groups. Captopril $(10 \mathrm{mg} / \mathrm{kg})$ and liguzinediol $(20 \mathrm{mg} /$ $\mathrm{kg}$ ) could also inhibit the increase of LVEDs. The original images of echocardiography were shown in Additional file 1: Figure S1.

\section{Effects of liguzinediol on hemodynamic parameters in MI rats}

As shown in Table 3 , LVSP, $\pm d \mathrm{dp} / \mathrm{dt}_{\max }, \mathrm{SBP}, \mathrm{DBP}$, and MAP significantly declined in MI rats, while LVEDP significantly increased when compared with the sham group. The results showed that the cardiac function of MI rats decreased obviously. After the treatment, Captopril $(10 \mathrm{mg} / \mathrm{kg})$, Digoxin $(0.032 \mathrm{mg} / \mathrm{kg})$ and liguzinediol $(5,10,20 \mathrm{mg} / \mathrm{kg})$ dramatically up-regulated the levels of LVSP, $\pm \mathrm{dp} / \mathrm{dt}_{\max }, \mathrm{SBP}, \mathrm{DBP}$ and MAP, and down-regulated LVEDP as well. It was indicated that the cardiac function of MI rats was significantly enhanced after treatment. The original images of hemodynamic parameters were shown in Additional file 2: Figure S2.

\section{Effects of liguzinediol on HMI and LVMI in MI rats}

After the hemodynamic detection, the weights of the whole heart and left ventricle were recorded. The heart mass index (HMI) and left ventricular mass index (LVMI) were also calculated. As shown in Table 4, both HMI and LVMI were significantly increased compared to the sham group, and left ventricular hypertrophy was observed in MI rats. All treatments could effectively reduce HMI and LVMI, while there was no significant difference between the MI group and the liguzinediol $(5 \mathrm{mg} / \mathrm{kg}$ ) group.
Effects of liguzinediol on the morphology of myocardial tissue in $\mathrm{Ml}$ rats

As shown in Fig. 2a, the results of H\&E staining indicated that the cardiomyocytes of sham-operated rats had clear lines. No hypertrophy, atrophy, fracture, cell degeneration, necrosis, and other lesions were observed. There was no inflammatory cell infiltration in the myocardial interstitium. In MI rats, severe degeneration and necrosis of cardiomyocytes were observed. Also, severe proliferation occurred in interstitial fibrous connective tissue with mild inflammatory cell infiltration. With the treatment of Captopril $(10 \mathrm{mg} / \mathrm{kg})$, Digoxin $(0.032 \mathrm{mg} / \mathrm{kg})$, and liguzinediol $(20 \mathrm{mg} / \mathrm{kg})$, cardiomyocytes in MI rats were mildly denatured, and the cytoplasm was loose. No hyperplasia, hypertrophy, atrophy, stromal edema, and inflammatory cell infiltration were observed. In liguzinediol (5, $10 \mathrm{mg} / \mathrm{kg}$ ) groups, moderate degeneration was observed in cardiomyocytes.

In addition, the ultrastructure of myocardial tissue was observed by transmission electron microscopy. As shown in Fig. 2b, the structure of mitochondrial inner and outer membranes in sham-operated rats was complete. The ridges were visible, without cavitation, and the sizes were the same. The $\mathrm{Z}$ and $\mathrm{M}$ lines of myofibril bundles are clear and arranged regularly. The nuclear structure is complete. While in MI rats, mitochondria swelled, ruptured, and formed vacuoles. The plasma membrane was partially broken, and the ridge was reduced, fractured, and scattered. Myofibrils were dissolved and disorganized. Also, the matrix density decreased and the intercellular space widened. However, all treatments could repair the mitochondrial damage in MI rats.

Table 1 The sequence of primers for real-time PCR

\begin{tabular}{ll}
\hline Gene name & Primer sequence $\mathbf{( 5}^{\prime} \mathbf{- 3}^{\mathbf{\prime}} \mathbf{)}$ \\
\hline TGF- $\beta 1$ & Sense: CCTGGAAAGGGCTCAACAC \\
& Antisense: CAGTTCTTCTCTGTGGAGCTGA \\
Smad2 & Sense: CAGGACGATTAGATGAGCTTGA \\
& Antisense: CCCCAATTTCAGAGCAAGT \\
Smad3 & Sense: CCTGCCACTGTCTGCAAG \\
& Antisense: GCAGCAAATTCCTGGTTGTT \\
Smad7 & Sense: ACCCCCATCACCTTAGTCG \\
& Antisense: AAATCCATCGGGTATCTGGA \\
CD105 & Sense: TGGGAGGCTAGGACTCAAGA \\
& Antisense: TTGTGCTAGTCAAGGTGAGGAG \\
GAPDH & Sense: TGTTGCCATCAACGACCCCTT \\
& Antisense: CTCCACGACATACTCAGCA \\
\hline
\end{tabular}


Table 2 Effects of liguzinediol on echocardiographic parameters in MI rats

\begin{tabular}{|c|c|c|c|c|c|c|c|c|}
\hline \multirow[t]{2}{*}{ Parameters } & \multirow[t]{2}{*}{ Dose $(\mathrm{mg} / \mathrm{kg})$} & \multirow[t]{2}{*}{ Sham } & \multirow[t]{2}{*}{ MI } & \multirow{2}{*}{$\begin{array}{l}\text { Captopril } \\
10\end{array}$} & \multirow{2}{*}{$\begin{array}{l}\text { Digoxin } \\
0.032\end{array}$} & \multicolumn{3}{|l|}{ Liguzinediol } \\
\hline & & & & & & 5 & 10 & 20 \\
\hline \multirow[t]{3}{*}{ EF (\%) } & Before & $74.88 \pm 5.35$ & $43.49 \pm 10.42^{* *}$ & $49.46 \pm 9.18^{* *}$ & $42.51 \pm 4.71^{* *}$ & $48.13 \pm 9.59^{* *}$ & $47.18 \pm 10.39^{* *}$ & $46.73 \pm 9.84^{* *}$ \\
\hline & After & $74.75 \pm 3.35$ & $40.41 \pm 12.21^{* *}$ & $56.96 \pm 13.57^{\# * *}$ & $49.37 \pm 8.7^{* *}$ & $51.9 \pm 10.47^{\# * *}$ & $54.01 \pm 8.96^{\# * *}$ & $54.34 \pm 7.06^{\# \# * * *}$ \\
\hline & D-value & $-0.13 \pm 4.41$ & $-3.08 \pm 11.41$ & $7.50 \pm 8.02^{\# *}$ & $6.87 \pm 7.01^{\# *}$ & $3.77 \pm 5.91$ & $6.84 \pm 6.77^{\# *}$ & $7.60 \pm 8.88^{\# *}$ \\
\hline \multirow[t]{3}{*}{ LVFS (\%) } & Before & $45.1 \pm 4.81$ & $22.51 \pm 6.21^{* *}$ & $26.21 \pm 5.65$ & $21.95 \pm 2.75^{* *}$ & $25.43 \pm 5.81^{* *}$ & $24.83 \pm 6.09^{* *}$ & $24.5 \pm 5.96^{* *}$ \\
\hline & After & $45.11 \pm 3.07$ & $21.08 \pm 7.13^{* *}$ & $31.82 \pm 9.03^{\# \# * *}$ & $26.55 \pm 5.65^{* *}$ & $28.16 \pm 6.47^{\# * *}$ & $29.48 \pm 5.69^{\# \# * *}$ & $29.62 \pm 4.71^{\# \# * *}$ \\
\hline & D-value & $0.02 \pm 4.31$ & $-1.42 \pm 6.81$ & $5.61 \pm 5.27^{\# *}$ & $4.61 \pm 4.61^{\# *}$ & $2.73 \pm 3.56$ & $4.65 \pm 4.16^{\# *}$ & $5.11 \pm 5.60^{\# *}$ \\
\hline \multirow[t]{3}{*}{ LVEDd $(\mu l)$} & Before & $246.41 \pm 33.12$ & $369.15 \pm 72.01^{* *}$ & $329.81 \pm 105.51^{*}$ & $341.19 \pm 45.66^{*}$ & $343.17 \pm 77.95^{* *}$ & $323.75 \pm 54.36^{* *}$ & $319.9 \pm 88.49^{*}$ \\
\hline & After & $313.72 \pm 64.81$ & $499.06 \pm 110.08^{* *}$ & $409.29 \pm 142.54$ & $458.63 \pm 48.54$ & $450.5 \pm 94.66^{* *}$ & $445.75 \pm 143.86^{*}$ & $425.03 \pm 69.42^{* *}$ \\
\hline & D-value & $67.30 \pm 69.74$ & $129.91 \pm 97.63$ & $79.48 \pm 102.45$ & $117.44 \pm 55.89$ & $107.32 \pm 60.47$ & $122.00 \pm 109.33$ & $105.13 \pm 64.13$ \\
\hline \multirow[t]{3}{*}{ LVEDs $(\mu l)$} & Before & $62.56 \pm 18.13$ & $214.87 \pm 77.82^{* *}$ & $178.92 \pm 78.14^{* *}$ & $180.27 \pm 37.10^{* *}$ & $183.64 \pm 72.31^{* *}$ & $173.44 \pm 55.05^{* *}$ & $174.88 \pm 67.36^{* *}$ \\
\hline & After & $79.20 \pm 24.57$ & $306.92 \pm 126.73^{* *}$ & $186.91 \pm 113.1^{\# \# * *}$ & $227.96 \pm 39.82^{* *}$ & $223.55 \pm 97.08^{* *}$ & $214.27 \pm 117.18^{* *}$ & $196.44 \pm 55.52^{\# * *}$ \\
\hline & D-value & $16.65 \pm 17.50$ & $92.05 \pm 109.06^{*}$ & $7.99 \pm 65.86$ & $47.69 \pm 33.76$ & $39.91 \pm 62.72$ & $40.83 \pm 69.18$ & $21.55 \pm 40.55$ \\
\hline \multirow[t]{3}{*}{ SV $(\mu \mathrm{l})$} & Before & $183.86 \pm 23.50$ & $154.28 \pm 34.94^{*}$ & $150.89 \pm 32.99^{*}$ & $160.91 \pm 58.60^{*}$ & $159.53 \pm 23.84^{*}$ & $150.31 \pm 33.73^{*}$ & $145.01 \pm 36.39^{*}$ \\
\hline & After & $234.52 \pm 42.30$ & $192.14 \pm 39.13^{*}$ & $222.38 \pm 54.3$ & $230.67 \pm 40.01^{\#}$ & $226.94 \pm 37.46$ & $231.49 \pm 40.72^{\#}$ & $228.59 \pm 33.71^{\#}$ \\
\hline & D-value & $47.66 \pm 62.07$ & $37.86 \pm 48.96^{*}$ & $71.49 \pm 49.23$ & $69.75 \pm 47.24$ & $67.41 \pm 27.00$ & $81.17 \pm 52.41$ & $83.58 \pm 46.71^{\#}$ \\
\hline \multirow[t]{3}{*}{$\mathrm{CO}(\mathrm{ml} / \mathrm{min})$} & Before & $78.39 \pm 17.95$ & $56.76 \pm 13.26^{* *}$ & $61.93 \pm 19.52$ & $68.02 \pm 29.40^{*}$ & $62.7 \pm 10.2^{*}$ & $60.63 \pm 19.4^{*}$ & $64.29 \pm 17.28$ \\
\hline & After & $99.69 \pm 18.28^{* *}$ & $70.41 \pm 12.16^{* *}$ & $91.11 \pm 26.4^{\#}$ & $92.57 \pm 28.01^{\#}$ & $91.32 \pm 16.46^{\# \#}$ & $95.77 \pm 22.52^{\# \#}$ & $100.41 \pm 15.71^{\# \#}$ \\
\hline & D-value & $19.76 \pm 24.93$ & $13.65 \pm 18.81$ & $29.18 \pm 22.59$ & $24.54 \pm 19.31$ & $28.62 \pm 13.37$ & $35.15 \pm 20.47^{\#}$ & $36.11 \pm 19.31^{\#}$ \\
\hline
\end{tabular}

Sham, sham-operated; MI, myocardial infarction; Before, before administration; After, after administration for 8 weeks; D-value =after-before; EF, ejection fraction; LVFS, left ventricular fractional shortening; LVEDd, LV end-diastolic dimension; LVEDs, LV end-systolic dimension; SV, stroke volum; CO, cardiac output, CO = SV $\times$ HR (heart rate)

Data are shown as the mean $\pm S D(n=10) .{ }^{*} P<0.05,{ }^{* *} P<0.01$, compared to Sham group; ${ }^{\#} P<0.05,{ }^{\# \#} P<0.01$, compared to Ml group

\section{Effects of liguzinediol on extracellular matrix remodeling in $\mathrm{MI}$ rats}

The deposition of collagen fibers in the left ventricular was detected by Masson staining. As shown in Fig. 3a, the myocardial fibers in sham-operated rats were orderly arranged, and there were rare blue fibrotic tissues. In MI rats, a large number of cardiomyocytes were necrotic, and collagen fibers were significantly increased. Captopril $(10 \mathrm{mg} / \mathrm{kg})$, Digoxin $(0.032 \mathrm{mg} / \mathrm{kg})$ and liguzinediol $(5,10,20 \mathrm{mg} / \mathrm{kg})$ could effectively reduce collagen deposition and myocardial fibrosis.
Besides, the level of hydroxyproline (HYP) dramatically up-regulated in MI rats, and the increase was reversed by Captopril, Digoxin, and liguzinediol (Fig. 3b). Similarly, the contents of collagen I and III significantly increased in MI rats, and the deposition could be reduced by all treatments (Fig. 3c). As shown in Fig. 3d, the expressions of matrix metalloproteinases (MMPs) MMP2, MMP9, and TIMP1 were detected by western blot. Captopril, Digoxin, and liguzinediol could inhibit the declines of MMP2, MMP9, and TIMP1 in MI rats.

Table 3 Effects of liguzinediol on hemodynamic parameters in MI rats

\begin{tabular}{|c|c|c|c|c|c|c|c|c|}
\hline Group & $\begin{array}{l}\text { Dose (mg/ } \\
\text { kg) }\end{array}$ & LVSP (mmHg) & $\begin{array}{l}\text { LVEDP } \\
(\mathrm{mmHg})\end{array}$ & $\begin{array}{l}+\mathrm{dp} \mathrm{dt}_{\max } \\
(\mathrm{mmHg} / \mathrm{s})\end{array}$ & $\begin{array}{l}-\mathrm{dp} \mathrm{dt}_{\max } \\
(\mathrm{mmHg} / \mathrm{s})\end{array}$ & $\mathrm{SBP}(\mathrm{mmHg})$ & $\mathrm{DBP}(\mathrm{mmHg})$ & MAP $(\mathrm{mmHg})$ \\
\hline Sham & - & $121.52 \pm 11.58$ & $12.80 \pm 4.36$ & $5486.62 \pm 1274.77$ & $-4514.28 \pm 1206.89$ & $127.43 \pm 13.73$ & $101.40 \pm 12.91$ & $110.08 \pm 12.24$ \\
\hline MI & - & $92.20 \pm 9.14^{* *}$ & $24.62 \pm 11.53^{* *}$ & $2879.57 \pm 699^{* *}$ & $-2602.23 \pm 709.79^{* *}$ & $94.94 \pm 14.45^{* *}$ & $68.32 \pm 9.91^{* *}$ & $77.19 \pm 10.94^{* *}$ \\
\hline Captopril & 10 & $117.70 \pm 10.11^{\# \#}$ & $11.07 \pm 5.43^{\# \#}$ & $5492.85 \pm 1056.12^{\# \#}$ & $-4690.98 \pm 407.66^{\# \#}$ & $112.86 \pm 14.92^{\# *}$ & $83.65 \pm 14.24^{\# * *}$ & $93.38 \pm 13.06^{\# \# * *}$ \\
\hline Digoxin & 0.032 & $107.94 \pm 10.11^{\# \# * * *}$ & $12.82 \pm 4.35^{\# \#}$ & $4334.41 \pm 805.68^{\# \# * *}$ & $-3688.32 \pm 679.12^{\# \#}$ & $117.25 \pm 14.03^{\# \#}$ & $89.02 \pm 14.92^{\# \#}$ & $98.43 \pm 13.30^{\# \#}$ \\
\hline \multirow[t]{3}{*}{ Liguzinediol } & 5 & $112.95 \pm 7.67^{\# \#}$ & $14.50 \pm 5.08^{\#}$ & $4716.70 \pm 761.77^{\# \#}$ & $-3902.99 \pm 593.81^{\# \#}$ & $117.29 \pm 13.67^{\# \#}$ & $86.93 \pm 12.69^{\# \# *}$ & $97.05 \pm 12.52^{\# \# *}$ \\
\hline & 10 & $116.26 \pm 12.91^{\# \#}$ & $13.77 \pm 4.13^{\#}$ & $4870.57 \pm 839.12^{\# \#}$ & $-4052.40 \pm 914.03^{\# \#}$ & $119.43 \pm 13.13^{\# \#}$ & $89.17 \pm 11.07^{\# \# *}$ & $99.26 \pm 11.34^{\# \#}$ \\
\hline & 20 & $119.48 \pm 7.28^{\# \#}$ & $13.47 \pm 5.15^{\#}$ & $5205.27 \pm 968.84^{\# \#}$ & $-4408.84 \pm 704.99^{\# \#}$ & $123.03 \pm 14.78^{\# \#}$ & $93.47 \pm 11.70^{\# \#}$ & $103.32 \pm 12.46^{\# \#}$ \\
\hline
\end{tabular}

Sham, sham-operated; MI, myocardial infarction; LVSP, LV systolic pressure; LVEDP, LV end-diastolic pressure; $+\mathrm{dp}_{\mathrm{dt}} \mathrm{dmax}_{\text {maximal }}$ mate of the increase of LV pressure; $-\mathrm{dp} / \mathrm{dt}_{\mathrm{max}}$, maximal rate of the decrease of LV pressure; SBP, systolic blood pressure; DBP, diastolic blood pressure; MAP, mean artery pressure Data are shown as the mean $\pm S D(n=10) .{ }^{*} \mathrm{P}<0.05,{ }^{* *} \mathrm{P}<0.01$, compared to Sham group; $\mathrm{H}<0.05,{ }^{\# \#} \mathrm{P}<0.01$, compared to Ml group 
Table 4 Effects of liguzinediol on HMI and LVMI in MI rats

\begin{tabular}{llcl}
\hline Group & Dose $(\mathbf{m g} / \mathbf{k g})$ & HMI $(\mathbf{m g} / \mathbf{g})$ & LVMI $(\mathbf{m g} / \mathbf{g})$ \\
\hline Sham & - & $2.63 \pm 0.21$ & $1.85 \pm 0.21$ \\
MI & - & $3.53 \pm 0.30^{* *}$ & $2.36 \pm 0.43^{* *}$ \\
Captopril & 10 & $2.88 \pm 0.31^{\# \# *}$ & $1.99 \pm 0.21^{\#}$ \\
Digoxin & 0.032 & $2.9 \pm 0.13^{\# \# * *}$ & $2.06 \pm 0.09^{\# * *}$ \\
Liguzinediol & 5 & $2.95 \pm 0.44^{\# \#}$ & $2.09 \pm 0.31$ \\
& 10 & $2.69 \pm 0.23^{\# \#}$ & $1.95 \pm 0.18^{\#}$ \\
& 20 & $2.69 \pm 0.20^{\# \#}$ & $1.92 \pm 0.16^{\# \#}$
\end{tabular}

Sham, sham-operated; MI, myocardial infarction; HMI, heart mass index, $\mathrm{HMI}=\mathrm{HM}$ (heart mass)/BM (body mass); LVMI, left ventricular mass index, LVMI = LVM (left ventricular mass)/BM

Data are shown as the mean $\pm S D(n=10) .{ }^{*} P<0.05$, ${ }^{* *} P<0.01$, compared to Sham group; ${ }^{\mathrm{P}}<0.05,{ }^{\# \#} \mathrm{P}<0.01$, compared to $\mathrm{Ml}$ group
Effects of liguzinediol on the Renin-AngiotensinAldosterone System (RAAS) in MI rats

Activation of RAAS increases the amount of available circulating blood in the early stages of heart failure. While with the development of heart failure, the activation of RAAS can cause several harmful effects on patients. The levels of AngII, ALD, and PRA in serum were detected by Elisa kits. As shown in Fig. 4a-c, AngII, ALD, and PRA increased significantly in MI rats compared with shamoperated rats. However, all treatments down-regulated the levels of AngII, ALD, and PRA. The protective effect of liguzinediol was dose-dependent.

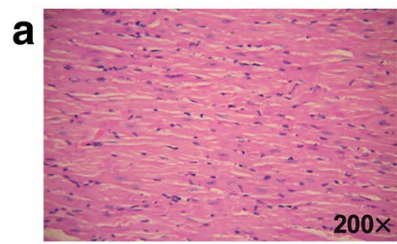

Sham

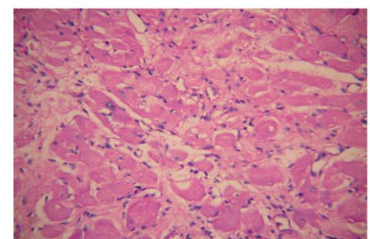

Liguzinediol (5 mg/kg)

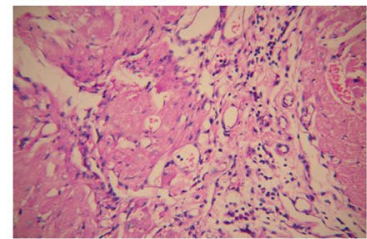

MI

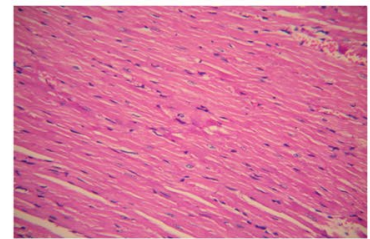

Captopril

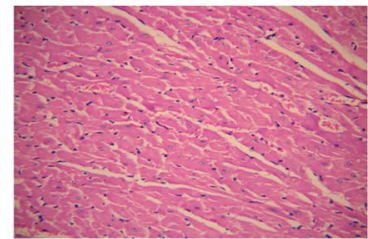

Digoxin
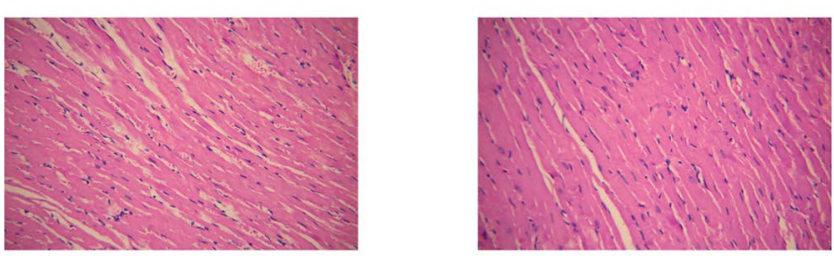

Liguzinediol (10 mg/kg)

Liguzinediol (20 mg/kg)

b

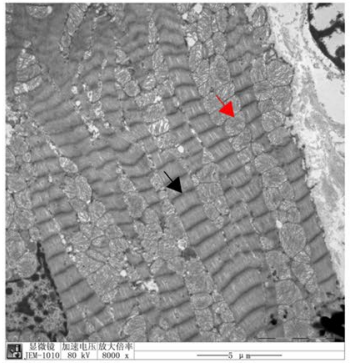

Sham

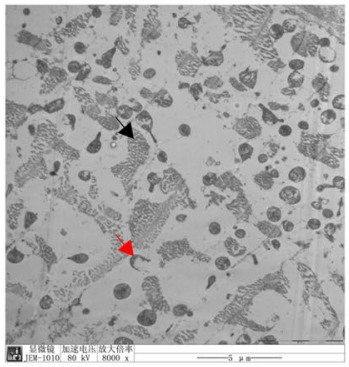

MI

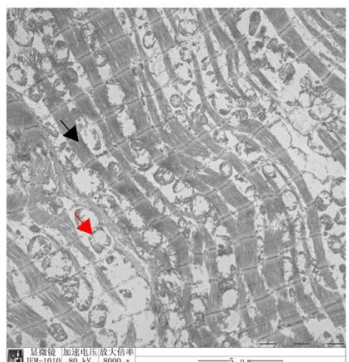

Captopril

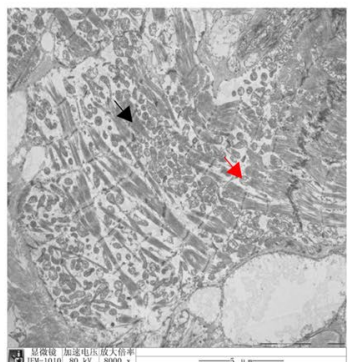

Digoxin
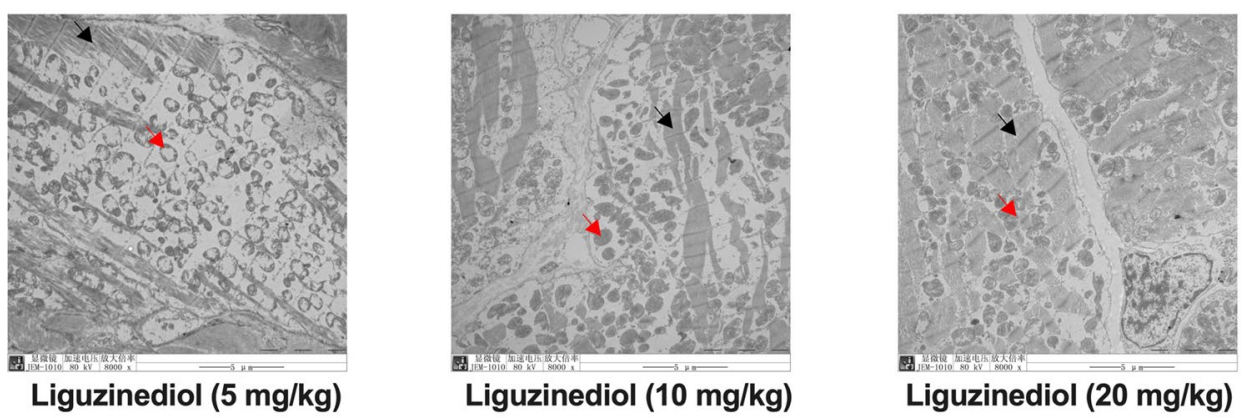

Fig. 2 Effects of liguzinediol on of myocardial tissue in MI rats. a The morphology of myocardial tissue was stained by H\&E ( $\times 200)$. b The ultrastructure of myocardial tissue was observed by transmission electron microscopy $(\times 8000)$ 


\section{Effects of liguzinediol on pro-inflammatory factors in MI rats}

Inflammation plays an essential role in the pathogenesis of heart failure. Pro-inflammatory cytokines produced by cells can cause left ventricular dysfunction, ventricular remodeling, and myocardial cell necrosis to accelerate the development of heart failure further. The results showed IL-1 $\beta$, IL- 6 , and TNF- $\alpha$ dramatically increased in MI rats. Compared with the MI group, all treatments could effectively reduce the level of IL- 6 and TNF- $\alpha$. While only Digoxin $(0.032 \mathrm{mg} / \mathrm{kg})$ and liguzinediol (10, $20 \mathrm{mg} / \mathrm{kg}$ ) could significantly inhibit the increase of IL-1 $\beta$ in $\mathrm{MI}$ rats (Fig. 4d-f).

\section{Effects of liguzinediol on oxidative stress in MI rats}

Oxidative stress maintains the balance between the prooxidation and anti-oxidation systems in cells. Excessive reactive oxygen species (ROS) can destroy the structure and function of myocardial cell membranes, which leads to myocardial cell necrosis. As shown in Fig. 4g, the level of MDA significantly improved in MI rats, and the enhance was reversed by all treatments. Conversely, Captopril $(10 \mathrm{mg} / \mathrm{kg})$, Digoxin $(0.032 \mathrm{mg} / \mathrm{kg})$ and liguzinediol $(5,10,20 \mathrm{mg} / \mathrm{kg})$ all increased the level of SOD in MI rats (Fig. 4h).

\section{Effects of liguzinediol on the TGF- $\beta 1 /$ Smads pathway in MI rats}

As shown in Fig. 5a, the level of TGF- $\beta$ in serum significantly increased in MI rats. The treatments with Captopril $(10 \mathrm{mg} / \mathrm{kg})$, Digoxin $(0.032 \mathrm{mg} / \mathrm{kg})$ and liguzinediol $(5,10,20 \mathrm{mg} / \mathrm{kg})$ could effectively reduce the serum TGF- $\beta$. Then the expressions of proteins involved in the TGF- $\beta 1 /$ Smads pathway were detected by western blot (Fig. 5c). The result showed the expressions of TGF$\beta 1, p-S m a d 2, p-S m a d 3$ and CD105 were dramatically activated in MI rats, and the increases were reversed by Captopril, Digoxin, and liguzinediol. Smad7 could inhibit the phosphorylation of Smad2 and Smad3. All treatments significantly promoted the expression of Smad7 in MI rats. Also, all treatments effectively reduced the mRNA levels of TGF- $\beta 1$, Smad2, Smad3, CD105 and increased the Smad7 mRNA (Fig. 5b).

\section{Discussion}

Heart failure has become a severe problem affecting human health worldwide, and myocardial infarction is one of the important causes of heart failure [19]. Ligation of coronary arteries is a commonly used method to establish a rat model of heart failure caused by MI [20]. In this study, we carried echocardiography combined with arterial intubation to determine the cardiac function of MI rats. Echocardiography can display the anatomical structure and ventricular wall movement of the heart in real-time, which can evaluate systolic and diastolic functions of LV [21]. The femoral artery cannula was operated to measure changes in the blood pressure of MI rats. The combination could comprehensively evaluate the changes in the cardiac function of MI rats. According to observations, $\mathrm{EF}<55 \%$ was used as the basis for assessing the success of the HF model. Because when the EF is lower than $30 \%$, it has been defined as severe HF, and it is meaningless to rely on drugs only [22]. The results of echocardiography and hemodynamics showed that liguziendiol could increase cardiac output and improve the systolic and diastolic functions of the heart in MI rats.

Heart failure is mainly manifested in progressive decrease of cardiac pumping function and remodeling of the ventricular cavity [23]. The core mechanism of $\mathrm{HF}$ is ventricular remodeling, which includes the remodeling of cardiomyocytes and extracellular matrix primarily [24]. Myocardial extracellular matrix remodeling is the result of imbalances in collagen production and degradation, as well as abnormal changes in collagen configuration and arrangement [25]. HYP is unique to collagen fibers, and the content of myocardial HYP can reflect the degree of myocardial fibrosis. The abnormal increase of HYP and collagen in myocardial tissue is the key to myocardial fibrosis [26]. The collagens present in the myocardial stroma are primarily collagen fibers type I and type III [27]. Collagen I is mainly consisted of coarse fibers with strong tension, while collagen III is fine-mesh and highly elastic. The ratio of collagen I/III can reflect myocardial stiffness [28]. Our results revealed that liguzinediol could effectively suppress the extracellular matrix remodeling and the degree of myocardial fibrosis, which enhanced myocardial compliance of MI rats. In addition, MMPs and TIMPs comprise an endogenous regulatory system that maintains the homeostasis of the extracellular matrix [29]. Several studies have reported that there was no change of MMPs activity in the early stages of compensatory cardiac hypertrophy. However, in the stage of heart failure, the increase of MMPs was positively correlated with the impairment of systolic function and the expansion of the ventricular cavity [30-32]. In this study, liguzinediol could inhibit extracellular matrix remodeling by regulating the dynamic balance of MMPs and TIMPs.

RAAS is a central system that regulates blood vessel tension, blood volume, and cardiovascular function. RAAS also plays an indispensable part in the pathogenesis of heart failure [33]. Many studies have confirmed that AngII, ALD, and PRA, the main ingredients in RAAS, significantly increased among heart failure [34-36]. Moreover, numerous clinical trials have shown that angiotensin-converting enzyme inhibitors can slow the development of heart failure, reduce morbidity and mortality 

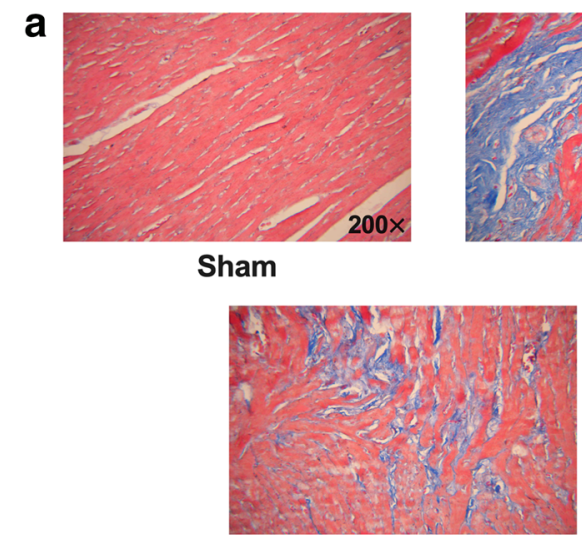

Liguzinediol (5 mg/kg)

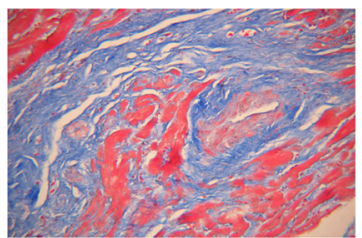

MI

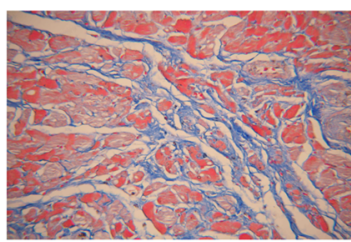

Captopril

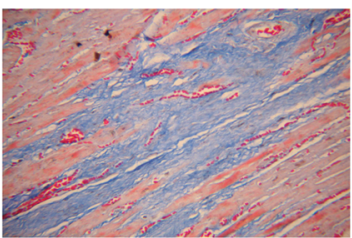

Digoxin

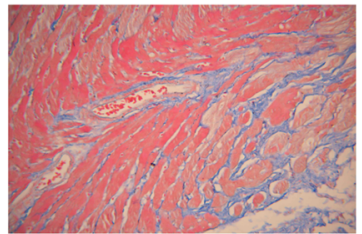

Liguzinediol $(10 \mathrm{mg} / \mathrm{kg})$

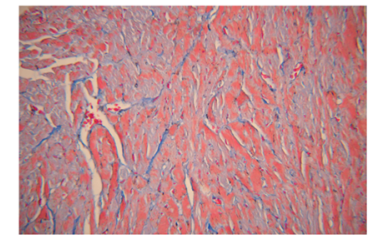

Liguzinediol (20 mg/kg)

b

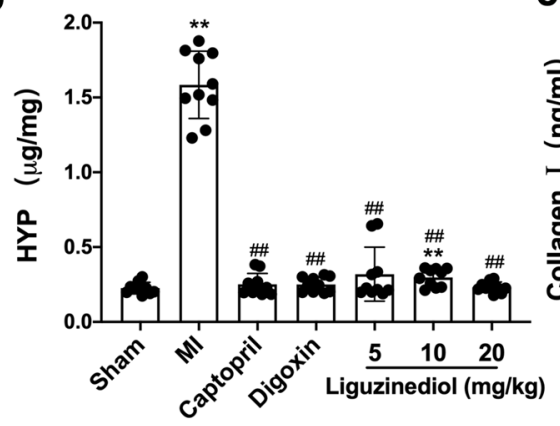

C
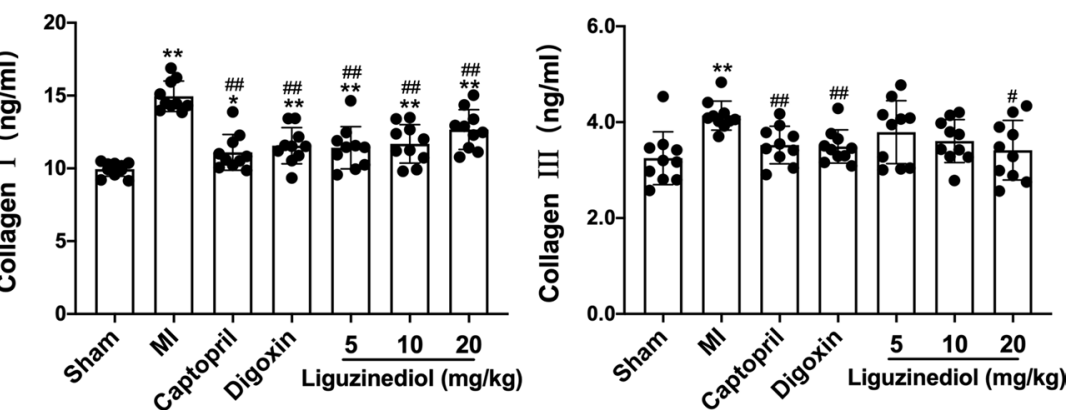

d

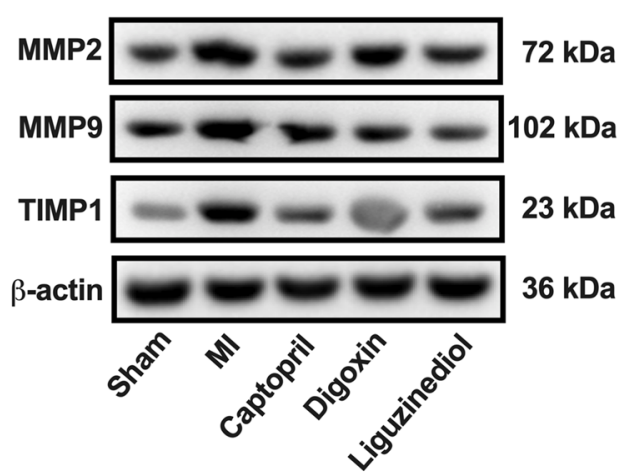

Fig. 3 Effects of liguzinediol on extracellular matrix remodeling in MI rats. a The deposition of collagen fibers was stained by Masson ( $\times 200)$. b The level of HYP in myocardial tissue was detected by kits $(n=10)$. c The levels of collagen I and III in serum were detected by Elisa kits $(n=10)$. $\mathbf{d}$ The expressions of MMP2, MMP9 and TIMP1 in myocardial tissue were detected by western blot $(n=3)$. Data are shown as the mean $\pm S D$. ${ }^{*} P<0.05$, ${ }^{* * P}<0.01$, compared to Sham group; ${ }^{\#} P<0.05,{ }^{\#} P<0.01$, compared to Ml group

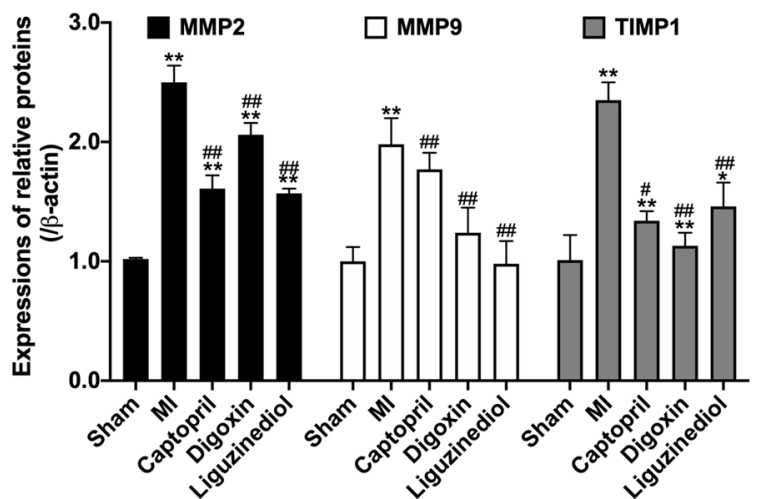

of cardiovascular diseases [37, 38]. Upon RAAS is activated in MI, high levels of renin and Ang II stimulate the produce of pro-inflammatory cytokines, which may cause left ventricular dysfunction, ventricular remodeling, and myocardial cell necrosis to further accelerate the development of HF [39]. Therefore, when explaining the mechanism of HF, inflammation is an indispensable important component. During the development of 


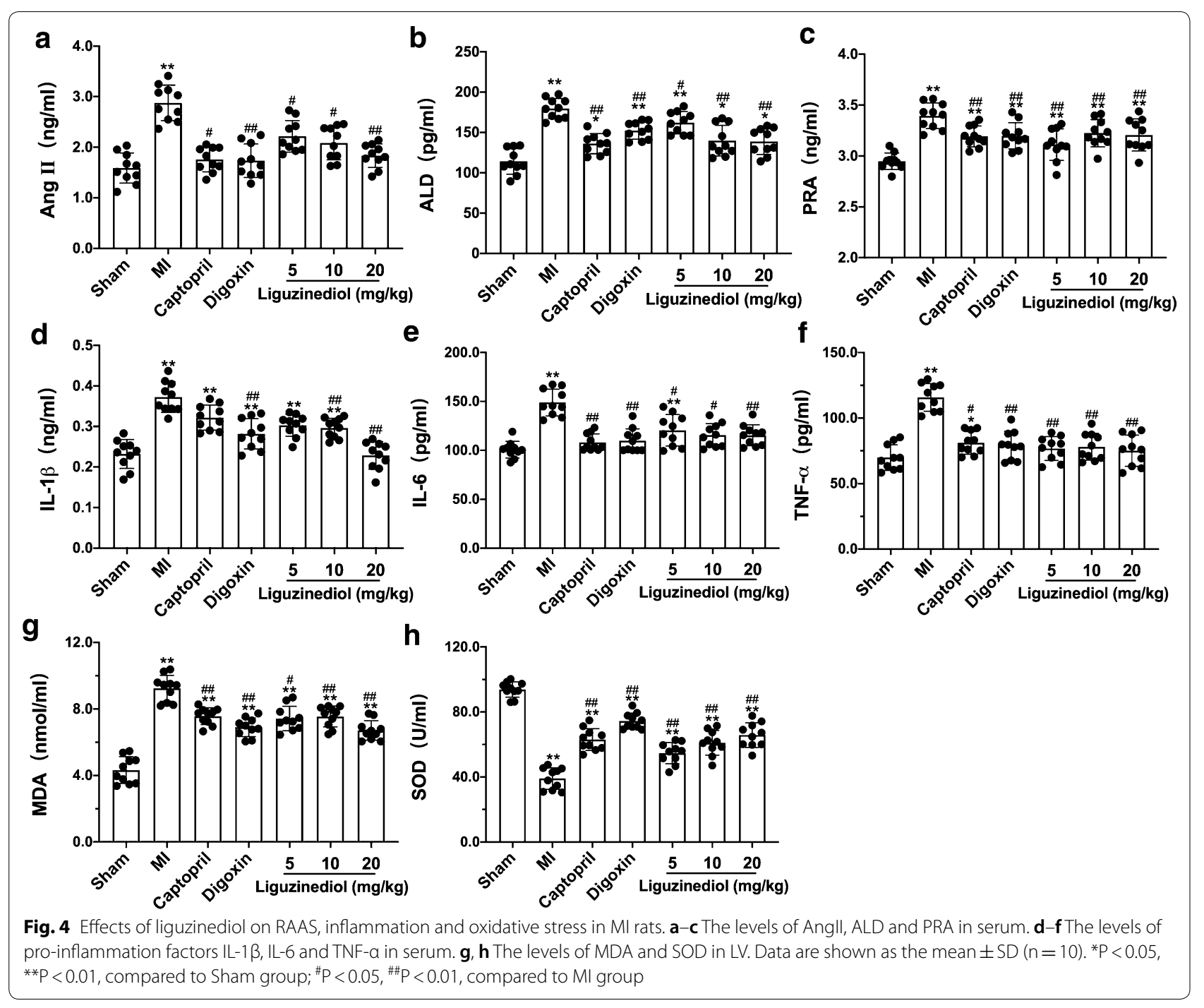

systems. Stimulated by inflammatory cytokines (such as IL-6, TNF- $\alpha$ ), vascular endothelial cells release nitric oxide, and neutrophils produce large amounts of oxygen free radicals [42]. Excessive ROS can cause damage to the structure and function of the myocardial cell membrane, which may lead to myocardial cell necrosis and accelerate the process of HF [43]. The activity of SOD decreases in the serum of patients with HF, accompanied by an increase in MDA production, which indicates that the dynamic balance of ROS production and clearance is disrupted [44]. Based on our experimental results, we found liguzinediol could prevent HF by regulating RAAS, reducing inflammation, and inhibiting oxidative stress.

TGF- $\beta 1$ is the central regulator of ventricular remodeling, which is involved in the process of myocardial fibrosis by regulating myocardial growth, myofibroblast activation, and extracellular matrix generation [45]. The intracellular TGF- $\beta 1$ pathway is regulated by proteins in the Smad family. Many cardiac dysfunctions are related to changes in the TGF- $\beta 1 /$ Smads pathway [46]. Likewise, the TGF- $\beta 1 /$ Smads pathway has connections to RAAS, inflammation, and extracellular matrix [47]. With the treatment of liguzinediol, the expressions of the TGF- $\beta 1 /$ Smads pathway were lowered in MI rats. It was suggested that the effect of liguzinediol on improving ventricular remodeling was related to the TGF- $\beta 1 /$ Smads pathway. However, we did not confirm whether liguzinediol directly suppressed the expression of TGF- $\beta 1$, which should be referred to in our future study. The anti-HF drugs used in the clinic can cause serious side effects. The safety window of cardiac glycosides is very narrow, ACEI can cause transient deterioration of renal function, and long-term use of diuretics is prone to electrolyte disorders. In this study, we revealed that liguzinediol exhibited protective effects on HF caused by MI. With 


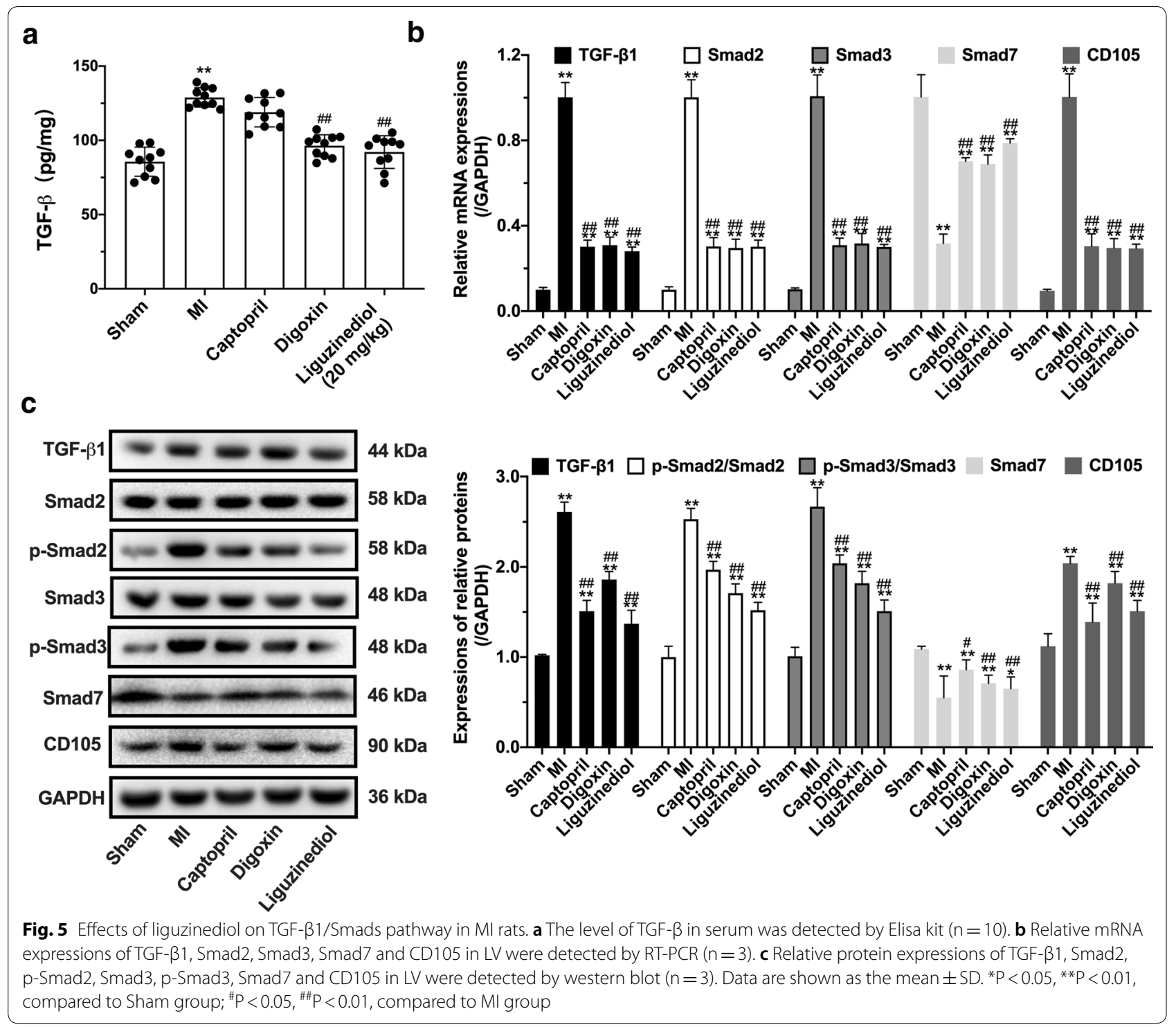

the low toxicity and good water solubility, liguzinediol is a promising candidate for the development of new antiHF drugs.

\section{Conclusion}

In this study, we revealed that liguzinediol could improve cardiac function by inhibiting the activation of RAAS, suppressing the production of pro-inflammatory cytokines, and reducing oxidative stress. It may provide new insight into the molecular mechanisms for liguzinediol on preventing HF. Nevertheless, to develop liguzinediol as an eligible therapeutic agent in the clinic, more mechanisms of liguzinediol involved in preventing HF are required to be detected in future studies.

\section{Supplementary information}

Supplementary information accompanies this paper at https://doi. org/10.1186/s13020-020-00345-7.

Additional file 1: Figure S1. The original images of echocardiography. (A) Sham group; (B) Myocardial infarction (MI) group; (C) Captopril (10 mg/kg) group; (D) Digoxin (0.032 mg/kg) group; (E) liguzinediol (5 mg/ $/ \mathrm{kg}$ ) group;

(F) liguzinediol (10 mg/kg) group; (G) liguzinediol (20 mg/kg) group.

Additional file 2: Figure $\mathbf{S 2}$. The original images of hemodynamic parameters in Ml rats. (A) Sham group; (B) Myocardial infarction (MI) group; (C) Captopril (10 mg/kg) group; (D) Digoxin (0.032 mg/kg) group; (E) liguzinediol $(20 \mathrm{mg} / \mathrm{kg})$ group.

\section{Abbreviations}

ACEl: Angiotensin-converting enzyme inhibitors; ALD: Aldosterone; Angll: Angiotensinll; CO: Cardiac output; DBP: Diastolic blood pressure; $+\mathrm{dp} / \mathrm{dt}_{\text {max }}$ : Maximal rate of the increase of $L V$ pressure; $-d p / d t_{\text {max }}$ : Maximal rate of the decrease of LV pressure; EF: Ejection fraction; H\&E: Hematoxylin and eosin; HF: 
Heart failure; HMI: Heart mass index; HR: Heart rate; HYP: Hydroxyproline; IL-1 1 : Interleukin-1 $\beta$; IL-6: Interleukin-6; LV: Left ventricular; LVEDd: LV end-systolic dimension; LVEDs: LV end-systolic dimension; LVEDP: LV end-diastolic pressure; LVFS: LV fractional shortening; LVMI: Left ventricular mass index; LVSP: LV systolic pressure; MAP: Mean artery pressure; MDA: Malondialdehyde; MI: Myocardial infarction; MMPs: Matrix metalloproteinases; PRA: Plasma renin activity; RAAS: Renin-Angiotensin-Aldosterone System; ROS: Reactive oxygen species; RT-PCR: Real-time polymerase chain reaction; SBP: Systolic blood pressure; SOD: Superoxide dismutase; SV: Stroke volume; TGF- $\beta 1$ : Transforming growth factor- $\beta 1$; TNF-a: Tumor necrosis factor-a.

\section{Acknowledgements \\ Not applicable.}

\section{Authors' contributions}

Conceptualization, QC and YL; Data curation, QC and DZ; Formal analysis, WZ and $Y Z$; Funding acquisition, $\mathrm{HB}$ and $\mathrm{YL}$; Methodology, YB, and QM; Project administration, QC and YL; Resources, YL and DZ; Software, QM; Supervision, QC, DZ, YL, and HB; Validation, DZ and QC; Writing —original draft, QC and $\mathrm{DZ}$; Writing - review and editing, QC, DZ, YL, and HB. All authors read and approved the final manuscript.

\section{Funding}

This work was supported by the National Natural Science Foundation of China (No. 81174029), the Open Project Program of Jiangsu Key Laboratory for Pharmacology and Safety Evaluation of Chinese Materia Medicine (JKLPSE 201809), the Project of the Priority Academic Program Development of Jiangsu Higher Education Institutions (PAPD), the Qing Lan Project, the 14th 'Six talent peaks' project in Jiangsu Province (WSN-015) and 'Six One Project' of Jiangsu commission of health (LGY2018054).

\section{Availability of data and materials}

The datasets used and/or analysed during the current study are available from the corresponding author on reasonable request.

\section{Ethics approval and consent to participate}

All procedures were performed in accordance with the guidelines of the Nanjing University of Chinese Medicine ethics committee.

\section{Consent for publication}

Not applicable.

\section{Competing interests}

The authors confirm that this article content has no conflict of interest.

\section{Author details}

'School of Pharmacy, Nanjing University of Chinese Medicine, Xianlin Avenue, Qixia District, Nanjing 210023, Jiangsu, China. ${ }^{2}$ School of Medicine and Life Sciences, Nanjing University of Chinese Medicine, Xianlin Avenue, Qixia District, Nanjing 210023, Jiangsu, China. ${ }^{3}$ Jiangsu Key Laboratory for Pharmacology and Safety Evaluation of Chinese Materia Medica, Nanjing University of Chinese Medicine, Nanjing 210023, China. ${ }^{4}$ Key Laboratory on Biosafety, Nanjing Institute of Environmental Sciences, Ministry of Ecology and Environment, Nanjing 210042, China.

Received: 31 March 2020 Accepted: 7 June 2020

Published online: 15 June 2020

\section{References}

1. Tribouilloy C, Rusinaru D, Leborgne L, Mahjoub H, Szymanski C, Houpe $D$, et al. In-hospital mortality and prognostic factors in patients admitted for new-onset heart failure with preserved or reduced ejection fraction: a prospective observational study. Arch Cardiovasc Dis. 2008;101 (4):226-34.

2. Gandhi SK, Powers JC, Nomeir AM, Fowle K, Kitzman DW, Rankin KM, et al. The pathogenesis of acute pulmonary edema associated with hypertension. N Engl J Med. 2001;344(1):17-22.

3. Zhao W, Zhao D, Yan R, Sun Y. Cardiac oxidative stress and remodeling following infarction: role of NADPH oxidase. Cardiovasc Pathol. 2009;18(3):156-66.
4. Zhu Y, Sun R, Dong E. Heart failure research in China: current status and future direction. Sci Bull. 2016;61(23):1793-801.

5. Coma-Canella I, Castano S, Nasarre E. Heart failure. Current pharmacologic treatment. Rev Med Univ Navarra. 2005;49(3):41-7.

6. McDonough AA, Wang J, Farley RA. Significance of sodium pump isoforms in digitalis therapy. J Mol Cell Cardiol. 1995;27(4):1001-9.

7. Mimran A, Ribstein J. Angiotensin converting enzyme inhibitors and renal function. J Hypertens Suppl. 1989;7(5):S3-9.

8. Shan CX, Li W, Wen HM, Wang XZ, Zhu YH, Cui XB. Identification of liguzinediol metabolites in rats by ultra performance liquid chromatography/ quadrupole-time-of-flight mass spectrometry. J Pharm Biomed Anal. 2012;62:187-90.

9. Cheng D, Zhou Y, Li W, Shan CX, Chai C, Cui XB, et al. Identification, characterization, synthesis and quantification of related impurities of liguzinediol. J Chromatogr Sci. 2015;53(8):1280-8.

10. Chen L, XuY, Li W, Wu H, Luo Z, Li X, et al. The novel compound liguzinediol exerts positive inotropic effects in isolated rat heart via sarcoplasmic reticulum Ca2+ ATPase-dependent mechanism. Life Sci. 2012;91(11-12):402-8.

11. Wu X, Qi X, Lu Y, Lin C, Yuan Y, Zhu Q, et al. Liguzinediol protects against cardiac fibrosis in rats in vivo and in vitro. Biomed Pharmacother. 2016;80:260-7.

12. Zhu HH, Chen YQ, Cheng D, Li W, Wang TL, Wen HM, et al. Synthesis and positive inotropic activity evaluation of liguzinediol metabolites. Bioorg Med Chem Lett. 2016;26(3):882-4.

13. Li Y, Song P, Zhu Q, Yin QY, Ji JW, Li W, et al. Liguzinediol improved the heart function and inhibited myocardial cell apoptosis in rats with heart failure. Acta Pharmacol Sin. 2014;35(10):1257-64.

14. Yin $H Q$, Wang $B$, Zhang JD, Lin HQ, Qiao Y, Wang R, et al. Effect of traditional Chinese medicine Shu-Mai-Tang on attenuating TNFalpha-induced myocardial fibrosis in myocardial ischemia rats. J Ethnopharmacol. 2008;118(1):133-9.

15. Prabhu SD, Chandrasekar B, Murray DR, Freeman GL. Beta-adrenergic blockade in developing heart failure: effects on myocardial inflammatory cytokines, nitric oxide, and remodeling. Circulation. 2000;101(17):2103-9.

16. Ruetten H, Gehring D, Hiss K, Schindler U, Gerl M, Busch AE, et al. Effects of combined inhibition of the $\mathrm{Na}+-\mathrm{H}+$ exchanger and angiotensinconverting enzyme in rats with congestive heart failure after myocardial infarction. Br J Pharmacol. 2005;146(5):723-31.

17. Ren J, Yang M, Qi G, Zheng J, Jia L, Cheng J, et al. Proinflammatory protein CARD9 is essential for infiltration of monocytic fibroblast precursors and cardiac fibrosis caused by Angiotensin II infusion. Am J Hypertens. 2011;24(6):701-7.

18. Li X, Li C, Ji X, Song Z, Wang L, Zhang J, et al. Huang-Lian-Jie-Du-Tang inhibits myocardial remodeling in a rat model of metabolic syndrome. J Ethnopharmacol. 2008;119(2):259-65.

19. Dargie H. Heart failure post-myocardial infarction: a review of the issues. Heart. 2005;91 Suppl 2:ii3-6 (discussion ii31, ii43-8).

20. Fu YH, Lin QX, Li XH, Fei HW, Shan ZX, Huang XZ, et al. A novel rat model of chronic heart failure following myocardial infarction. Methods Find Exp Clin Pharmacol. 2009;31(6):367-73.

21. Fuji J, Watanabe H, Kato K. Detection of the site and extent of the left ventricular asynergy in myocardial infarction by echocardiography and B-scan imaging. Jpn Heart J. 1976;17(5):630-48.

22. Agac MT, Agac S, Korkmaz L, Erkan H, Turan T, Bektas H, et al. A simple angiographic index to predict adverse clinical outcome associated with acute myocardial infarction. Turk Kardiyol Dern Ars. 2014;42(4):321-9.

23. Cohn JN, Ferrari R, Sharpe N. Cardiac remodeling — concepts and clinical implications: a consensus paper from an international forum on cardiac remodeling. Behalf of an International Forum on Cardiac Remodeling. J Am Coll Cardiol. 2000;35(3):569-82.

24. Janicki JS, Brower GL, Gardner JD, Chancey AL, Stewart JA Jr. The dynamic interaction between matrix metalloproteinase activity and adverse myocardial remodeling. Heart Fail Rev. 2004;9(1):33-42.

25. Rutschow S, Li J, Schultheiss HP, Pauschinger M. Myocardial proteases and matrix remodeling in inflammatory heart disease. Cardiovasc Res. 2006;69(3):646-56.

26. Matsubara LS, Matsubara BB, Okoshi MP, Franco M, Cicogna AC. Myocardial fibrosis rather than hypertrophy induces diastolic dysfunction in renovascular hypertensive rats. Can J Physiol Pharmacol. 1997;75(12):1328-34. 
27. Pauschinger M, Doerner A, Remppis A, Tannhauser R, Kuhl U, Schultheiss HP. Differential myocardial abundance of collagen type I and type III mRNA in dilated cardiomyopathy: effects of myocardial inflammation Cardiovasc Res. 1998;37(1):123-9.

28. Pauschinger M, Knopf D, Petschauer S, Doerner A, Poller W, Schwimmbeck PL, et al. Dilated cardiomyopathy is associated with significant changes in collagen type I/III ratio. Circulation. 1999;99(21):2750-6.

29. Bourboulia D, Stetler-Stevenson WG. Matrix metalloproteinases (MMPs) and tissue inhibitors of metalloproteinases (TIMPs): positive and negative regulators in tumor cell adhesion. Semin Cancer Biol. 2010;20(3):161-8.

30. Friehs I, Margossian RE, Moran AM, Cao-Danh H, Moses MA, del Nido PJ. Vascular endothelial growth factor delays onset of failure in pressureoverload hypertrophy through matrix metalloproteinase activation and angiogenesis. Basic Res Cardiol. 2006;101(3):204-13.

31. Kim HE, Dalal SS, Young E, Legato MJ, Weisfeldt ML, D'Armiento J. Disruption of the myocardial extracellular matrix leads to cardiac dysfunction. J Clin Invest. 2000;106(7):857-66.

32. Mujumdar VS, Smiley LM, Tyagi SC. Activation of matrix metalloproteinase dilates and decreases cardiac tensile strength. Int J Cardiol. 2001;79(2-3):277-86.

33. Kuno T, Ueyama H, Fujisaki T, Briasouli A, Takagi H, Briasoulis A. Metaanalysis evaluating the effects of Renin-Angiotensin-Aldosterone System blockade on outcomes of heart failure with preserved ejection fraction. Am J Cardiol. 2020. https://doi.org/10.1016/j.amjcard.2020.01.009.

34. Lu M, Qin Q, Yao J, Sun L, Qin X. Induction of LOX by TGF-beta1/Smad/ AP-1 signaling aggravates rat myocardial fibrosis and heart failure. IUBMB Life. 2019;71(11):1729-39.

35. Lin XY, Xiao LZ, Gao LJ, Zhang HF. Effects of carvedilol on neurohormone and magnesium metabolism in patients with chronic heart failure. Zhonghua Xin Xue Guan Bing Za Zhi. 2005;33(11):995-7.

36. Wang F, Xu ZM, Wang L, Bian WY, Jia X, Duan B, et al. Beneficial neurohormonal profiles of beta-blockades in chronic left heart failure. Zhonghua Nei Ke Za Zhi. 2005;44(7):490-4.

37. Ahmed A. Use of angiotensin-converting enzyme inhibitors in patients with heart failure and renal insufficiency: how concerned should we be by the rise in serum creatinine? J Am Geriatr Soc. 2002;50(7):1297-300.

38. Chin MH, Wang JC, Zhang JX, Lang RM. Utilization and dosing of angiotensin-converting enzyme inhibitors for heart failure. Effect of physician specialty and patient characteristics. J Gen Intern Med. 1997;12(9):563-6.
39. Phillips MI, Kagiyama S. Angiotensin II as a pro-inflammatory mediator. Curr Opin Investig Drugs. 2002;3(4):569-77.

40. Sakata Y, Chancey AL, Divakaran VG, Sekiguchi K, Sivasubramanian N, Mann DL. Transforming growth factor-beta receptor antagonism attenuates myocardial fibrosis in mice with cardiac-restricted overexpression of tumor necrosis factor. Basic Res Cardiol. 2008;103(1):60-8.

41. Nishimura M, Hashimoto T, Kobayashi H, Fukukda T, Okino K, Yamamoto $\mathrm{N}$, et al. Possible involvement of TNF-alpha in left ventricular remodeling in hemodialysis patients. J Nephrol. 2003;16(5):641-9.

42. Tamion F, Richard V, Bonmarchand G, Leroy J, Hiron M, Daveau M, et al. Reduced synthesis of inflammatory cytokines by a free radical scavenger after hemorrhagic shock in rats. Crit Care Med. 2000;28(7):2522-7.

43. Yan X, Xun M, Dou X, Wu L, Zhang F, Zheng J. Activation of $\mathrm{Na}(+)-\mathrm{K}(+)$ ATPase with DRm217 attenuates oxidative stress-induced myocardial cell injury via closing $\mathrm{Na}(+)-\mathrm{K}(+)$-ATPase/Src/Ros amplifier. Apoptosis. 2017;22(4):531-43.

44. Klimiuk A, Zalewska A, Sawicki R, Knapp M, Maciejczyk M. Salivary oxidative stress increases with the progression of chronic heart failure. J Clin Med. 2020;9(3):769.

45. Villar AV, Cobo M, Llano M, Montalvo C, Gonzalez-Vilchez F, Martin-Duran $\mathrm{R}$, et al. Plasma levels of transforming growth factor-beta1 reflect left ventricular remodeling in aortic stenosis. PLOS ONE. 2009;4(12):e8476.

46. Zhang R, Zhang YY, Huang XR, Wu Y, Chung AC, Wu EX, et al. C-reactive protein promotes cardiac fibrosis and inflammation in angiotensin IIinduced hypertensive cardiac disease. Hypertension. 2010;55(4):953-60.

47. Lan HY. Diverse roles of TGF-beta/Smads in renal fibrosis and inflammation. Int J Biol Sci. 2011;7(7):1056-67.

\section{Publisher's Note}

Springer Nature remains neutral with regard to jurisdictional claims in published maps and institutional affiliations.
Ready to submit your research? Choose BMC and benefit from:

- fast, convenient online submission

- thorough peer review by experienced researchers in your field

- rapid publication on acceptance

- support for research data, including large and complex data types

- gold Open Access which fosters wider collaboration and increased citations

- maximum visibility for your research: over 100M website views per year

At BMC, research is always in progress.

Learn more biomedcentral.com/submissions 